\title{
Design thinking e cultura maker na educação: contribuição metodológica no desenvolvimento de competências para o século XXI
}

Design thinking and maker culture in education: methodological contributions in developing skills for the 21st century

Maria Paula Marcon da Cruz

Universidade Anhembi Morumbi

mariapaulamarcon@live.com

Suzete Venturelli

Universidade Anhembi Morumbi

suzeteventurelli@gmail.com

\author{
(n)
}

a

PROJËTICA

\section{COMO CITAR ESTE ARTIGO:}

CRUZ, Maria Paula Marcon da; VENTURELLI, Suzete. Design thinking e cultura maker na educação: contribuição metodológica no desenvolvimento de competências para o século XXI. Projética, Londrina, v. 12, n. 2, p. 240-261, 2021.

DOI: 10.5433/2236-2207.2021v12n2p240

Submissão: 01-09-2020

Aceite: 20-01-2021

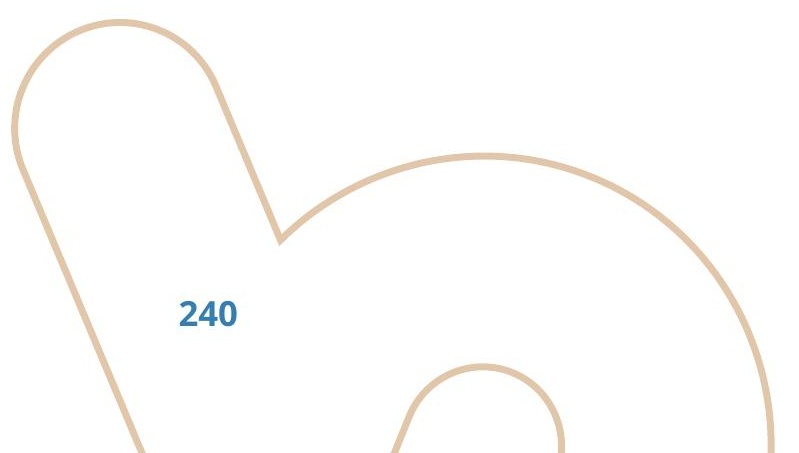


RESUMO: O artigo apresenta o processo e o resultado de uma experiência pedagógica com jovens aprendizes da educação básica entre 12 a 16 anos. Com vistas no desenvolvimento de competências socioemocionais por intermédio da aprendizagem ativa, a proposta parte de uma problemática real voltada a criação e a fabricação de um barco cenográfico, de modo a aplicar expertises do design ligadas a cultura maker e a técnicas de DIY, incluindo a utilização de tecnologias de fabricação digital como softwares de desenho vetorial, máquina de corte a laser e fresadora CNC.

Palavras-chave: Design Thinking. Metodologias ativas. Aprendizagem criativa. Culturamaker.

ABSTRACT: This article presents the process and the result of a pedagogical experience with young apprentices of basic education between 12 and 16 years old. With a view to the development of soft skills through active learning, our proposal starts from a real problem focused on the design and manufacturing of a scenography boat, in order to apply the design expertise linked to the maker culture and DIY techniques, including the use of digital manufacturing technologies such as vector drawing software, laser cutting machine and CNC router.

Keywords: Design Thinking. Active Methodologies. Creative Learning. Maker Culture.

\section{INTRODUÇÃO}

A relação entre design e processos educacionais vem sendo abordada em vários estudos e demonstra potencial de contribuição em diversas esferas da jornada educacional, apoiando instituições, docentes e discentes com recursos estruturais, tecnológicos e até mesmo estratégicos. Este artigo apresenta a contribuição do design de forma estratégica, sendo apropriado como recurso metodológico para aprendizagem ativa, com vistas de explorar o desenvolvimento de competências 
Projética, Londrina, v. 12, n. 2, p. 240-261, agosto 2021

técnicas e sobretudo competências comportamentais essenciais para a vida adulta, conhecidas como soft skills, termo popular no universo corporativo que se refere atitudes e comportamentos que ajudam a adquirir, consolidar e compartilhar conhecimentos entre pares no ambiente de trabalho. As soft skills fazem parte do grupo de competências socioemocionais e podem ser acessadas e ou ampliadas no indivíduo desde a infância, tendem a ser promovidas nos ambientes escolares por intermédio de vivências, o que fez com que fossem inseridas como competências essenciais da BNCC (Base Nacional Comum Curricular) homologada pelo MEC em 2017.

A fim exemplificar a relação entre design e educação, o artigo apresenta um relato de experiência referente a convergência de metodologias ativas de aprendizagem e recursos metodológicos do campo do design, a convergência vem sendo experimentado em um projeto intitulado Lab Lar que oferta oficinas no programa de contraturno escolar do Lar da Bênção Divina, organização não governamental, situada na cidade de São Paulo e que atende crianças e jovens em situação de vulnerabilidade social. O projeto Lab Lar admite jovens de 12 a 16 anos matriculados na educação básica e tem como objetivo o desenvolvimento de competências socioemocionais como a empatia, comunicação, criatividade, colaboração e autoconhecimento por intermédio de oficinas práticas.

A proposta do programa surgiu em resposta às demandas da instituição, que necessitava trabalhar o desenvolvimento de competências socioemocionais propostas na BNCC, bem como promover maior engajamento dos aprendizes na participação do projeto de contraturno escolar, ao passo que os mesmos se mostravam cansados do atual formato adotado de educação escolarizada. Em ocasião destes aspectos, a instituição tinha expectativa de oferecer um programa orientado a projetos, com características da cultura digital, e que permitisse aos jovens desenvolver soluções voltadas à melhoria de vida em suas escolas ou em seu bairro, a fim de despertar valores como a responsabilidade social. 
Para atender as demandas do programa, foi desenvolvido em 2018 um projeto pedagógico pelo designer e educador Me. Nivaldo Áureo Nascimento Silva ${ }^{1}$, coordenador do ÂnimaLab da unidade Santos da rede de laboratórios do Instituto ÂnimaSociesc de Inovação, Pesquisa e Cultura. O projeto é apoiado na $\mathrm{PBL}^{2}$ - Aprendizagem baseada em projetos - e no conceito da Aprendizagem Criativa de Seymour Papert do MIT Media Lab, se apropria do design como recurso metodológico para o desenvolvimento dos projetos.

Figura 1 - Estrutura do programa Lab Lar

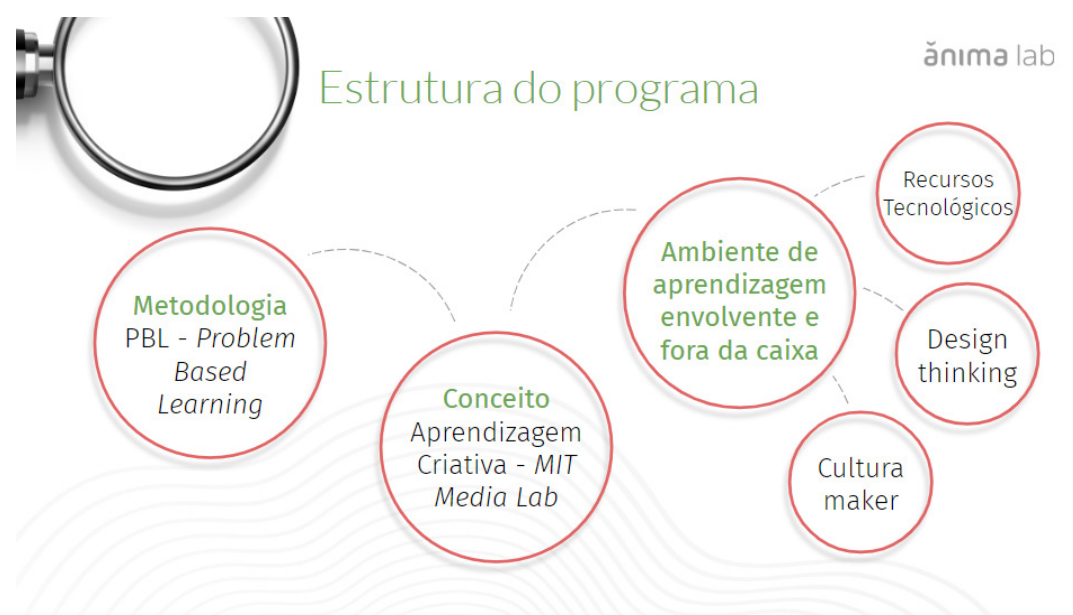

Fonte: Relatório semestral ÂnimaLab,(Santos, 2019.)

[1] Designer e Educador. Specialised Training for Trainers in University Pedagogy - University of Tampere, UTA, Finlândia, Mestre em Tecnologias da Inteligência e Design Digital - Puc SP, Graduado em Design pela UFSC, com ênfase no Design de Mídias Sociais. [2] A PBL (project based learning) é um método de aprendizagem ativa que se apoia na realização de projetos para resolução de problemas reais como elemento motivador para o aprendizado, o processo estimula os discentes a serem protagonistas no processo de construção do conhecimento, tendo o docente como um mentor que os norteia durante a jornada (BENDER, 2014). 
Projética, Londrina, v. 12, n. 2, p. 240-261, agosto 2021

O projeto pedagógico propõe a adoção do modelo mental do design thinking como abordagem durante as oficinas, que por intermédio da proposta de desafios reais, estimula os alunos a desenvolverem projetos que empregam entre outros recursos as tecnologias de fabricação digital e práticas da cultura maker, criando um ambiente envolvente que favorece o engajamento dos alunos em um processo prático, o que auxilia acessar os objetivos de aprendizagem.

O presente relato busca demonstrar novas perspectivas de contribuições do design para educação, que surge a partir do seguinte questionamento: O design como recurso metodológico pode contribuir na abordagem da aprendizagem ativa, sendo capaz de promover o alcance dos objetivos de aprendizagem presentes em projetos pedagógicos orientados ao desenvolvimento de soft skills?

Para levantar aspectos relevantes referentes à abordagem metodológica do design na educação e demonstrar evidências do alcance dos objetivos de aprendizagem inseridos no projeto pedagógico proposto pelo educador Nivaldo Silva, o artigo apresenta um relato do processo de um projeto que foi realizado nas oficinas Lab Lar com um grupo de 35 alunos divididos entre os turnos da manhã e da tarde. Durante o processo foi feito registro de imagens de cada etapa de seu desenvolvimento e colhido feedback com os aprendizes envolvidos sobre a experiência vivenciada a fim de levantar considerações em relação a eficiência da estratégia abordada.

\section{Design thinking como abordagem para a aprendizagem ativa}

A reformulação das políticas educacionais na última década abriu discussão de estratégias para a melhoria da qualidade de ensino no Brasil, trazendo diversas propostas para reformular o modelo. Um dos objetivos dessa reforma é oferecer aos discentes um maior preparo para enfrentar os desafios do mercado de trabalho que vem passando por grandes e constantes transformações nas últimas décadas por conta do advento tecnológico. 
A tecnologia que vem transformando o mercado de trabalho também provoca grandes transformações nos hábitos do estudante contemporâneo. Bacich e Moran (2018) apontam o desafio de atribuir sentido a educação escolarizada ao jovem da era digital, que tem acesso com um simples click a uma infinidade de informações, um mundo que se abre sem limitações espaciais, temporais e institucionais por intermédio da tela. A tecnologia entra neste contexto como um fator de distanciamento entre o aluno, o professor e as práticas tradicionais da escola, algo que pode ser revertido a favor da educação com novas práticas dentro e fora da sala de aula.

É notório que o modo tradicional do ensino vem apresentando falhas na forma como é ofertado, um dos aspectos está na contribuição para a competitividade entre discentes em sala de aula, ao passo que as atividades individuais dominam a maior parte do período em que o aprendiz permanece na escola, prática que vai de confronto com a história da evolução da humanidade, que segundo afirma Firmiano (2011), se dá em virtude da capacidade do homem de se organizar em grupos e coordenar esforços que promovem o aprendizado, o que vem garantido a permanência da espécie ao longo dos milênios. A própria história faz apontamentos da relevância e o aprendizado seja construído em pares.

No entanto, não se deve desprezar outro aspecto importante para a evolução do indivíduo, a autonomia. Autores como Dewey (1916), Freire (1996), Piaget (1998) e Papert (1994), entre outros, em suas diferentes teorias relacionadas aos processos de aprendizagem, partem da premissa de que a autonomia é inerente ao desenvolvimento do indivíduo e que este se constrói da capacidade de adaptação a situações vivenciadas em seu contexto. Ao criar instrumentos para a superação de obstáculos do cotidiano, o aprendiz evolui de acordo com as experiências e da complexidade dos desafios que enfrenta. 
Projética, Londrina, v. 12, n. 2, p. 240-261, agosto 2021

As teorias defendidas pelos autores citados evidenciam pressupostos da necessidade de adoção de novas práticas ao modelo convencional do ensino e apontam direcionamentos para nortear algumas mudanças tangíveis para promover transformações que possam ser significativas para os educandos, pois segundo Camargo e Daros (2018, p. 5):

[...] Essas teorias fornecem subsídios para uma pedagogia dinâmica, centrada na criatividade e na atividade discente, em uma perspectiva de construção do conhecimento, do protagonismo, do autodidatismo, da capacidade de resolução de problemas, do desenvolvimento de projetos, da autonomia e do engajamento no processo de ensino - aprendizagem por meio das metodologias de abordagem ativa.

Os apontamentos apresentados ao longo dessa reflexão em relação ao ensino e o perfil do estudante contemporâneo, buscam justificar algumas das mudanças que vêm sendo implantadas em tímida parcela das instituições de ensino, dentre elas a adoção das metodologias ativas de aprendizagem, abordagem que segundo Cortelazzo et al. (2018) se caracteriza por intermédio do protagonismo discente que atua como agente ativo no processo de aprendizagem, fator este que confere "um novo sentido a experiência em sala de aula de forma que a mesma torna-se um espaço privilegiado de convívio, compartilhamento e construção do conhecimento" (CORTELAZZO et al., 2018, p. 31) .

O docente tem um papel importante nesse processo, ao passo que deve propor projetos desafiadores, com temáticas aproximadas ao contexto social em que os aprendizes estão inseridos a fim de engajá-los, e a partir do desafio lançado, atuar como mediador durante o processo de aprendizagem.

O design se insere nesse contexto como recurso metodológico para a prática da aprendizagem ativa, ao passo que adota métodos e ferramentas que contemplam demandas desse processo. Bonsiepe (2011) fala que o fazer é 
inerente à natureza do design e que este se caracteriza pela intencionalidade que envolve o processo. O design é pautado por métodos, e o domínio destes configura as competências desenvolvidas pelos designers, que se expande do modo de fazer para o modo de pensar, o que de certa forma originou o design thinking. Segundo Kalena (2010) o design thinking se define como um modelo mental com intencionalidade em resolução de problemas, objetivando transformar desafios em oportunidades e Brown (2010) complementa que seus métodos se apoiam na capacidade do indivíduo em ser criativo e propor soluções para resolução de desafios complexos em diversas esferas, contemplando soluções no contexto social, ambiental e até econômico.

A abordagem do design thinking se apoia em conceitos que propiciam a criação de um ambiente fértil para a aprendizagem ativa, pois tem como pilares a empatia, colaboração e em especial a experimentação, conceitos que conduzem práticas que podem contribuir no impulsionamento da transformação esperada nas atitudes do aluno diante ao processo de aprendizagem, favorecendo a autonomia e protagonismo do mesmo, bem como na construção do conhecimento em pares, de forma coletiva.

\section{Aprendizagem criativa de Papert e o contexto da cultura maker}

Papert (1994), assim como o progressista Dewey e o construtivista Piaget, defendia que o aprendizado se desenvolve de forma mais efetiva ao se realizar tarefas associadas aos conteúdos ensinados, estreitando a relação entre a teoria e prática, colocando atividades manuais e criativas como destaque na jornada pedagógica para permitir ao aprendiz a experimentar as hipóteses teóricas e construir o aprendizado por intermédio das experiências vivenciadas. Papert também afirma que é importante compreender que para a aprendizagem ser significativa e produtora de sentido é necessário colocar o aprendiz frente a 
Projética, Londrina, v. 12, n. 2, p. 240-261, agosto 2021

resolução de problemas do mundo real, e envolvê-lo em um processo que considere o contexto no qual ele esteja inserido. Resnik (2020), em sua obra propõe que o contexto da aprendizagem deve ser repensado pelas instituições de ensino levando em consideração o fator afetivo e pode ser preparado pelo educador, sugerindo por intermédio da metáfora dos micromundos ${ }^{3}$ como este contexto pode ser construído apoiado no pensamento de Papert:

Chão baixo - A atividade deve ser iniciada com baixo grau de complexidade, para encorajar o aprendiz a participar do que é proposto, se sentindo seguro, sem medo de errar e ser julgado pelo professor ou pelos colegas, desta forma o aprendiz vai se envolvendo aos poucos no processo;

Teto alto - O Teto alto significa que a atividade precisa ser planejada de forma que se permita uma evolução no nível de complexidade ao passo que o aprendiz vai se envolvendo e avançando no processo;

Paredes distantes - Esse é o caráter que faz com que a atividade permita uma expansão para vertentes que se adequem ao contexto do aprendiz e o encoraje ir além, fechando desta forma um ciclo significativo da aprendizagem.

A partir de um contexto de aprendizagem estabelecido, Resnick (2020) explica que diferentemente do que acontece em atividades da aula em formato escolarizado, a atividade pautada na metáfora do micromundo consolida o aprendizado como produto fruto de um processo exploratório angariado pela postura ativa do aprendiz e da sua interação com o mundo. Esse processo consiste

[3] Micromundos é um conceito adotado por Papert para o desenvolvimento da linguagem logo, que oferece um ambiente de aprendizagem exploratória. O nome está relacionado à proposta de oferecer ao aprendiz a oportunidade de experienciar ambientes semelhantes aos do mundo real a fim de explorar o objeto a ser aprendido. 
na Aprendizagem Criativa, uma filosofia educacional cunhada no pensamento de Papert, o Construcionismo, que busca o desenvolvimento do aprendiz por intermédio do pensamento e da ação criativa, colaborativa e sistemática. A fim de guiar esse processo, Resnik (2020) propõe os quatro Ps da Aprendizagem Criativa, princípios norteadores que podem ser explorados com as práticas cultura maker:

Project - trabalhar com projetos desde a ideia à execução permite o aprendiz a construir conhecimento por intermédio da ação dentro desse processo;

Passion - o aprendizado se torna mais significativo quando se está envolvido no processo, ao explorar a paixão do aprendiz esse envolvimento é nutrido favorece o engajamento fazendo com que o aluno permaneça por mais tempo na atividade, fator que amplia a capacidade de retenção do conhecimento;

People - trabalhar em pares permite aos aprendizes o compartilhamento de ideias e a troca de conhecimento, enriquecendo a experiência do aprendizado;

Play - a jornada de aprendizagem deve ser divertida, a experiência do brincar tem aspecto exploratório que funciona como uma via para a criatividade e incentiva o aprendiz a assumir desafios e experimentar coisas novas.

A cultura maker propicia um ambiente fértil para se consolidar a aprendizagem criativa por um processo ativo, ela pode ser considerada um desdobramento tecnológico da a cultura DIY (Do It Yourself), envolvendo várias áreas do fazer criativo, explorando desde o artesanato e a marcenaria até a eletrônica avançada. O movimento parte do pressuposto de que as pessoas podem criar qualquer coisa por intermédio da experimentação e com as suas próprias habilidades, além de incentivar o compartilhamento de ideias, o que vem mudando o modo de se produzir artefatos, ao passo que assume cada vez mais o perfil de criação em rede, que segundo Anderson (2014) otimiza processos e cria um círculo virtuoso, que amplia a inovação e agrega maior valor às criações. 


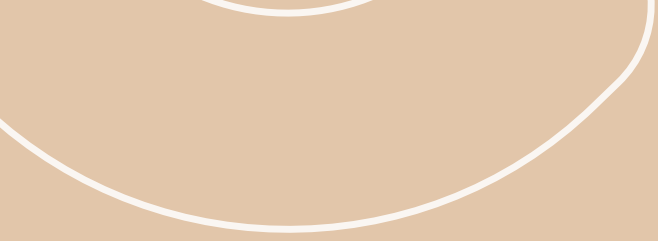

[...] Essas teorias fornecem subsídios para uma pedagogia dinâmica, centrada na criatividade e na atividade discente, em uma perspectiva de construção do conhecimento, do protagonismo, do autodidatismo, da capacidade de resolução de problemas, do desenvolvimento de projetos, da autonomia e do engajarmento no processo de ensino - aprendizagem por meio das metodologias de abordagem ativa (CAMARGO e DAROS, 2018, p.05).

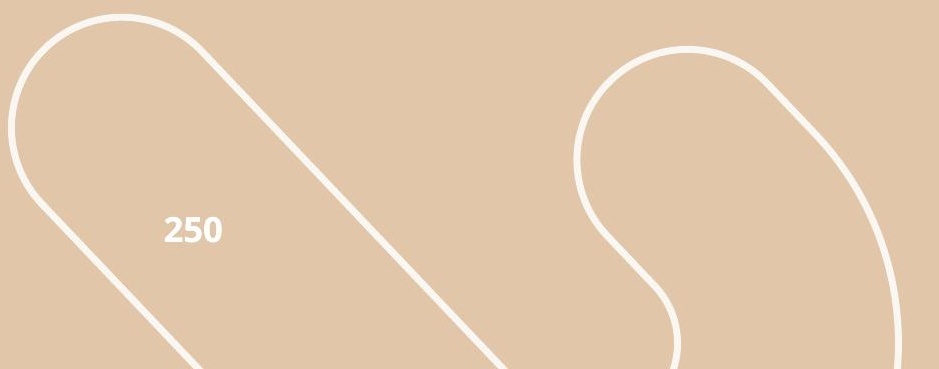


A cultura maker avança do conceito dos laboratórios de garagem que trabalhavam ideias isoladas e de pouco potencial por possuir meios escassos de produção, para um contexto mais atual, impulsionado pela revolução tecnológica, que segundo Anderson (2012) conferiu maior autonomia aos seus praticantes, considerando que os novos aparatos tecnológicos e os meios de comunicação contribui para a aceleração do processo de prototipagem, experimentação, compartilhamento e de produção de artefatos, facilidades viabilizadas por intermédio dos e veículos de comunicação online e equipamentos de fabricação digital como impressoras 3D, fresadoras CNC e máquinas de corte a laser.

O pensamento de colaboração e compartilhamento (people), do aprender fazendo e aprender com o erro a partir da experimentação (project), desenvolver projetos significativos a fim de criar produtos para atender às próprias demandas (passion) bem como o uso de tecnologias disruptivas para viabilizar projetos e experimentos (play), coloca a cultura maker como um importante vetor na abordagem da aprendizagem ativa e na construção de contextos para a aprendizagem criativa proposto por Papert.

\section{Design thinking e a prática da cultura maker nas oficinas Lab Lar}

As oficinas Lab Lar são realizadas semanalmente, com duração de 3 horas e contam com a presença de aproximadamente entre 17 participantes por turno. O relato é referente ao processo de desenvolvimento de um projeto que teve como ponto de partida o desafio apresentado aos aprendizes durante o segundo semestre de 2019: Criar peças cenográficas para o recital de fim de ano que aconteceria na Sala São Paulo, em dezembro do mesmo ano, com especial atenção a peça principal, um barco cenográfico que apresentava a problemática de ter que ser composto por peças que permitissem o mesmo ser montado bem como transportado de um lado para o outro do palco durante a encenação. 
Projética, Londrina, v. 12, n. 2, p. 240-261, agosto 2021

A metodologia Double Diamond norteou o processo de desenvolvimento do projeto protagonizado pelos aprendizes ao longo de treze semanas de atividades intensas. O Diamante Duplo (traduzido para o português) é um processo metodológico desenvolvido pelo British Design Council ${ }^{4}$ embasado no design thinking. A metodologia é estruturada em quatro etapas e recebeu esse nome por conta do processo divergente e convergente que caracterizam o fluxo de desenvolvimento delas, esse processo de dá ao considerar o pensamento lateral que é gerativo e o pensamento vertical que possui caráter analítico (PINHEIRO; ALT, 2012). Em cada etapa foram explorados métodos e ferramentas do design thinking para a formatação das atividades que viabilizaram a criação e construção do produto fruto do desafio, ao mesmo tempo que permitiam trabalhar os objetivos de aprendizagem relacionados ao desenvolvimento das competências soft skills, foco principal do projeto pedagógico proposto pelo Lab Lar. O processo seguiu as seguintes etapas:

Descoberta - A primeira fase do processo trabalha a descoberta, com atividades de investigativas que envolvem pesquisa e imersão em contexto para um melhor entendimento da problemática que envolve o desafio apresentado. Os aprendizes tomaram mão de técnicas como coleta de briefing, entrevistas em grupo e safari, a interação com essas técnicas permite explorar competências comunicacionais, dentre elas a escuta ativa e a empatia;

[4] British Design Concil é um órgão público do Reino Unido criado para apoiar a recuperação econômica da Grã-Bretanha no período pós-guerra, se consolidou como instituição e desde então tem como enfoque em melhorar a vida humana por intermédio do design. https:// www.designcouncil.org.uk (DESIGN COUNCIL UK, 2019) 
Figura 2 - Etapas de descoberta e definição - Briefing e discussão em grupo
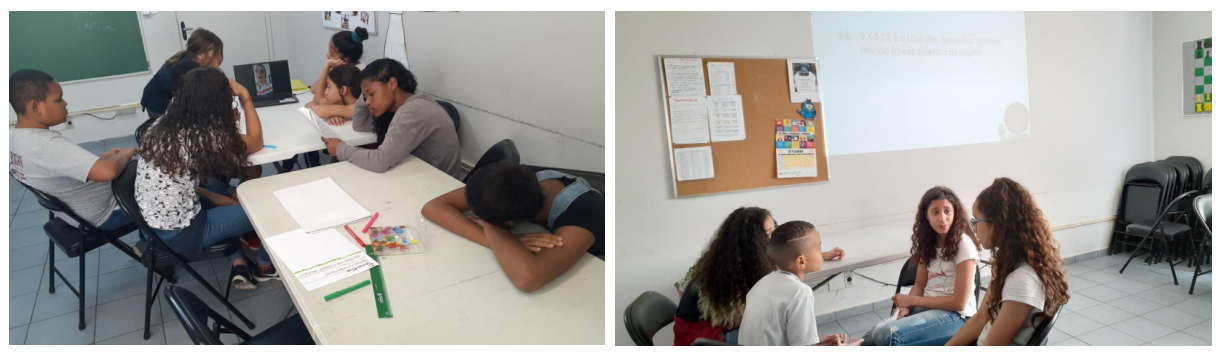

Fonte: As autoras, 2019.

Definição - A definição é um momento de análise e síntese, suas atividades vão além da exploração da capacidade analítica e o senso crítico, mas também desenvolve a capacidade de argumentação e consenso ao passo que os aprendizes precisam chegar em uma definição de forma coletiva para que proposta seja fruto de uma percepção construída sob várias óticas. As experiências vivenciadas na etapa de definição estimulam o início de uma jornada de autoconhecimento, que se estende ao longo do processo, isso acontece pelo fato de os aprendizes serem desafiados a lidar com suas emoções e com a pressão do grupo durante as atividades;

Desenvolvimento - Desenvolvimento é a etapa na qual aprendizagem ativa se torna consciente por parte dos aprendizes, pois nesta fase eles já se encontram imersos no contexto do desafio e por intermédio de ferramentas de ideação, os aprendizes são estimulados a propor ideias, fazendo com que sintam um grau maior de pertencimento no processo ao passo que a proposta de solução parte da ideia elaborada pelo grupo, o que incentiva o protagonismo. Nesse momento a competência explorada de maneira mais intencional é a criatividade, que acontece de forma coletiva, explorando a fluência e a flexibilidade de pensamento criativo com o auxílio de ferramentas usuais do design thinking como Brainstorm. 
Projética, Londrina, v. 12, n. 2, p. 240-261, agosto 2021

Figura 3 - Etapa de desenvolvimento - Processos de ideação e prototipagem
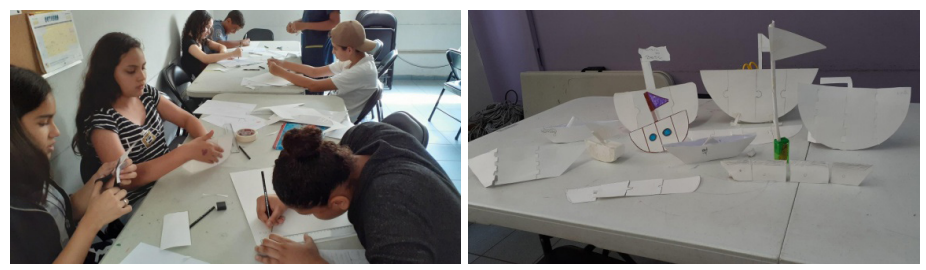

Fonte: As autoras, 2019.

Nessa etapa também se insere a prototipagem, onde os aprendizes são desafiados a materializar as ideias propostas durante a etapa anterior, é o momento do fazer com as próprias mãos, experimentando e explorando desde recursos simples como papel, tesoura, cartolina, isopor, materiais de sucata entre outros, até recursos mais avançados para fabricação digital, como cortadora a laser, fresadora CNC e modelagem e impressão 3D. Os laboratórios de cultura maker, chamados de makerspaces dão suporte importante nesta etapa, a interação com técnicas de prototipagem permite praticar e desenvolver competências como colaboração, a autonomia e o pensamento crítico intensamente;

Figura 4 - Etapa desenvolvimento - Fabricação da proposta final
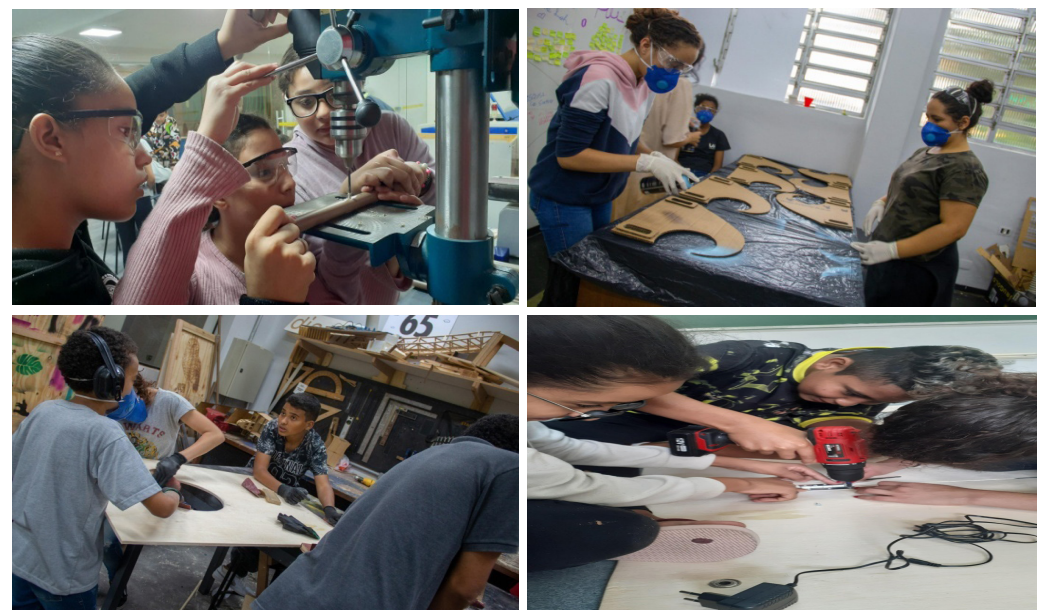

Fonte: As autoras, 2019. 
Entrega - A etapa de entrega é o momento em que o aprendizado se faz consciente de forma mais intensa, pois a cada etapa do processo os aprendizes são expostos a feedbacks que os induzem ao aperfeiçoamento da proposta, isso gera um processo cíclico de experimentar, compartilhar, refletir, imaginar experimentar... até que se conclua a etapa. Quando chega a etapa da entrega, os aprendizes são convidados a fazer uma reflexão inicialmente individual e depois conjunta de todo o processo, o que faz com que percebam como evoluíram durante a jornada, e tendem a concluir como os desafios enfrentados contribuíram na compreensão do aprendizado.

Figura 5 - Etapa de entrega - Finalização do projeto e estreia no recital

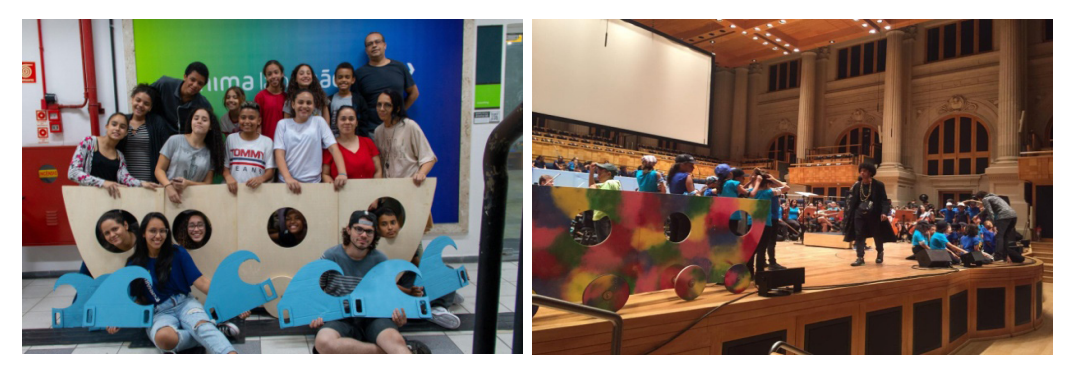

Fonte: As autoras, 2019.

\section{Considerações}

É possível considerar que a abordagem da metodologia PBL pode estar intimamente relacionada aos processos de design, ao passo que em ambas atividades o ato de projetor é inerente. A convergência entre as duas metodologias se torna coerente ao passo que a PBL como metodologia ativa aponta entre vários aspectos que o ato de projetar influi de forma efetiva no processo de aprendizagem, é perceptível que a metodologia se dedica em orientar o docente em relação ao 
Projética, Londrina, v. 12, n. 2, p. 240-261, agosto 2021

modo de ensinar por intermédio de projetos, no entanto não orienta os docentes de forma específica em relação ao passo a passo de como realizar um projeto, lacuna que pode ser preenchida com a adoção de metodologias projetuais do design pois estas são destinadas a este fim, o que foi exemplificado na experiência apresentada.

O relato demonstra que ao utilizar métodos e ferramentas do campo de atuação do design possibilitou trabalhar todos os objetivos de aprendizagem propostos pelo programa pedagógico desenvolvido para as oficinas Lab Lar, o que foi possível ao consolidar a exploração de cada um dos objetivos durante as etapas da atividade projetual protagonizada pelos aprendizes sob a orientação dos educadores envolvidos no processo:

Figura 7 - Relação da metodologia aplicada nas oficinas Lab Lar com as soft skills

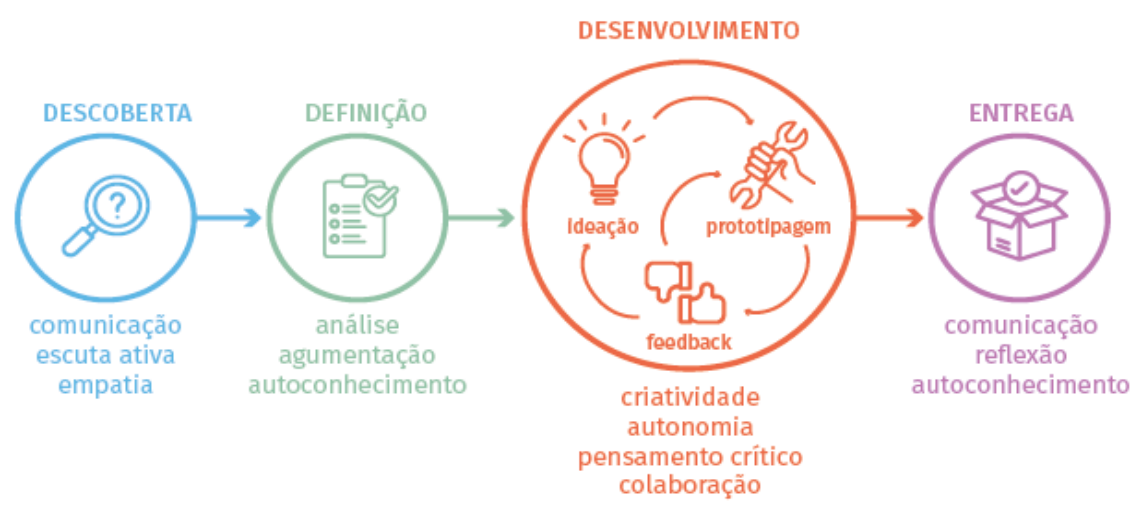

Fonte: As autoras (2020).

Desenvolvimento de soft skills - Conforme esquematizado na Figura 07, as principais competências comportamentais foram trabalhadas de forma intencional durante as etapas de desenvolvimento do projeto, se tornando possível por conta 
das características do design thinking, que apresenta aderência à exploração dessas competências propostas no projeto pedagógico. Durante cada etapa do projeto os aprendizes se mostraram capazes de explorar ferramentas e atividades propostas pautadas no design thinking e ao longo do processo já demonstraram por intermédio de relatos estarem percebendo o valor em se trabalhar em equipe e a necessidade de observar e ouvir as pessoas para entender suas reais necessidades. Ao final do projeto relataram estarem surpresos com a capacidade própria de criar e realizar propostas para resolver um problema;

Engajamento no projeto de contraturno - O engajamento se tornou visível ao passo que a maioria dos aprendizes se envolveram de forma ativa durante todo o processo, alguns trabalhavam no projeto mesmo em dias que as oficinas não eram oferecidas, o que evidencia o protagonismo do aprendiz ao tomar iniciativas e elaborar estratégias favorecendo o desenvolvimento do projeto mesmo sem a presença do mentor. Os aprendizes apontaram alguns elementos que foram essenciais para esse envolvimento, dentre eles o fato de que o produto fruto do projeto iria ser utilizado para um evento protagonizado por eles mesmos e apresentado para um público no qual família e amigos estariam presentes, esse fator demonstra como o elemento emocional é importante no processo de aprendizagem, como aponta as teorias da Aprendizagem Criativa. Outros elementos importantes percebidos foram o entusiasmo e a curiosidade provocados pelos conceitos da culturamaker e a exploração dos recursos desse universo auxiliou a manter os aprendizes imersos no processo, mesmo os menos interessados durante a etapa de descoberta e definição demonstraram grande interesse na etapa de desenvolvimento, principalmente em processos que foram trabalhadas as técnicas de prototipagem e da finalização da construção do produto;

Inserção na cultura digital - Ficou evidente a aprendizagem das ferramentas de fabricação digital explorada nesse projeto ao passo que os aprendizes foram capazes de executar todas as etapas da fabricação digital, desde a escolha da 
Projética, Londrina, v. 12, n. 2, p. 240-261, agosto 2021

tecnologia mais adequada para aquele projeto, que neste caso foi o uso da máquina corte a laser para as peças menores e da fresadora CNCrouter para as peças maiores, até a preparação dos arquivos digitais para as máquinas por intermédio de softwares de desenho vetorial. Alguns aprendizes inclusive se encorajaram a operar as máquinas sob supervisão do mentor e técnicos do makerspace.

É importante pontuar que o projeto Lab Lar não pretende e nem é capaz de oferecer aos jovens formação no campo do design, sabemos que existe uma longa jornada pedagógica que aborda teorias, filosofia e fundamentos do design, além das várias técnicas que envolve a formação de um profissional da área, nas oficinas Lab Lar, os aprendizes entram em contato apenas com alguns desses conhecimentos, apenas o necessário para se atingir a proposta pedagógica . A relação entre design e educação aqui é de interface para a prática da aprendizagem ativa. Podemos perceber por intermédio da experiência apresentada que o design tem grande potencial de contribuição para a educação, atendendo necessidades que se expandem além da elaboração de materiais de uso escolar, mobiliários, aparatos tecnológicos, editoriais didáticos e plataformas de ensino a distância. 0 design também pode ser estendido como elemento que possibilita a construção de contextos de aprendizagem significativos, atuando como interface entre docentes e discentes e o acesso aos seus objetivos de aprendizagem.

O relato abre margem para um amplo espectro de pesquisa em relação à possibilidade de recursos metodológicos do design como interface, ao passo que toda interface ao subsidiar o suprimento de uma necessidade humana promove interações e moldam comportamentos. As interações devem ser previstas e projetadas de forma consciente e intencional, algumas destas interações puderam ser percebidas e testadas por intermédio da atuação dos aprendizes na experiência relatada, no entanto há muito que se explorar. 
Design thinking e cultura... século XXI

CRUZ, M. P. M.; VENTURELLI, S.

Em que se refere ao comportamento resultante do contato com a interface, este deve sempre estar condicionado ao fim que a mesma se destina, que neste caso em particular visa o desenvolvimento socioemocional dos aprendizes, o que influencia diretamente no comportamento do indivíduo em suas relações sociais, comportamentos estes que já estão sendo percebidos por outros professores de projeto de contraturno, bem como por alguns pais e pelos próprios aprendizes participantes das oficinas, sem deixar de mencionar o relato das evidências coletadas por esta educadora que conduz o projeto. 
Projética, Londrina, v. 12, n. 2, p. 240-261, agosto 2021

1. ANDERSON, Chris. Makers: a nova revolução digital. Rio de Janeiro: CampusElsevier, 2014.

2. BACICH, Lilian; MORAN, José. Metodologias ativas para uma educação inovadora: uma abordagem teórico-prática. Porto Alegre: Penso, 2018.

3. BENDER. Aprendizagem baseada em projeto (2014) disponível em http://revista.faculdadeprojecao.edu.br/index.php/Projecao5/article/ download/673/579 acesso em Out 2019

4. BONSIEPE, Gui. Design, cultura e sociedade. São Paulo: Ed. Blücher, 2011.

5. DESIGN COUNCIL UK. Disponível em https://www.designcouncil.org.uk acesso Out , 2019.

6. BROWN, Tim. Design Thinking: uma metodologia poderosa para decretar o fim das velhas ideias. Rio de Janeiro. Elsevier, 2010.

7. CAMARGO, Fausto; DAROS, Thuinie. A sala de aula inovadora: estratégias pedagógicas para fomentar o aprendizado ativo (desafios da Educação). Porto Alegre: Penso, 2018.

8. CORTELAZZO, Angelo Luiz et al. Metodologias ativas e personalizadas de aprendizagem: Para refinar seu cardápio metodológico. Rio de Janeiro: Alta Books, 2018.

9. DESIGN COUNCIL UK. What is the framework for innovation? design council's evolved double diamond. 2019. Disponível em: https://www. designcouncil.org.uk/news-opinion/what-framework-innovation-designcouncils-evolved-double-diamond. Acesso em: 10 out. 2019. 
Design thinking e cultura... século XXI CRUZ, M. P. M.; VENTURELLI, S.

10. DEWEY, John. Democracy and education. An introduction to the philosophy of education. New York: Macmillan Company, 1916.

11. FIRMIANO, Edinaldo Pereira. Aprendizagem cooperativa na sala de aula. 2011. Disponível em: https://docplayer.com.br/14290327-Aprendizagemcooperativa-na-sala-de-aula.html. Acesso em: 10 out. 2019

12. FREIRE, Paulo. Pedagogia da autonomia: saberes necessários à prática educativa. São Paulo: Paz e Terra, 1996.

13. KALENA, Fernanda. Design thinking para educadores em português. 2010. Disponível em: http://cfjl.com.br/images/Blogs/ti/20160506_DT_Livro_ Completo.pdf. Acesso em: 10 out. 2019.

14. PAPERT, Seymour. A máquina das crianças: repensando a escola na era da informática. Porto Alegre: Artes Médicas, 1994.

15. PIAGET, Jean. Sobre a pedagogia. São Paulo: Casa do Psicólogo, 1998.

16. PINHEIRO, Tennyson; ALT, Luis. Design Thinking Brasil: empatia, colaboração e experimentação para pessoas, negócios e sociedade. São Paulo: Elsevier, 2012.

17. RESNICK, Mitchel. Jardim de infância para a vida toda: por uma aprendizagem criativa, mão na massa e relevante para todos. Porto Alegre: Penso, 2020.

18. Santos. Relatório semestral ÂnimaLab. disponível em http://www3. eca.usp.br/sites/default/files/form/biblioteca/acervo/producaoacademica/003016069.pdf, acesso Out 2019 